\title{
Drug problems among homeless individuals in Toronto, Canada: prevalence, drugs of choice, and relation to health status
}

\author{
Michelle N Grinman ${ }^{1,2^{*}}$, Shirley Chiu', Donald A Redelmeier ${ }^{2,3}$, Wendy Levinson ${ }^{2}$, Alex Kiss ${ }^{4}$, \\ George Tolomiczenko ${ }^{5,6}$, Laura Cowan ${ }^{7}$, Stephen W Hwang ${ }^{1,2}$
}

\begin{abstract}
Background: Drug use is believed to be an important factor contributing to the poor health and increased mortality risk that has been widely observed among homeless individuals. The objective of this study was to determine the prevalence and characteristics of drug use among a representative sample of homeless individuals and to examine the association between drug problems and physical and mental health status.

Methods: Recruitment of 603 single men, 304 single women, and 284 adults with dependent children occurred at homeless shelters and meal programs in Toronto, Canada. Information was collected on demographic characteristics and patterns of drug use. The Addiction Severity Index was used to assess whether participants suffered from drug problems. Associations of drug problems with physical and mental health status (measured by the SF-12 scale) were examined using regression analyses.

Results: Forty percent of the study sample had drug problems in the last 30 days. These individuals were more likely to be single men and less educated than those without drug problems. They were also more likely to have become homeless at a younger age (mean 24.8 vs. 30.9 years) and for a longer duration (mean 4.8 vs. 2.9 years). Marijuana and cocaine were the most frequently used drugs in the past two years (40\% and $27 \%$, respectively). Drug problems within the last 30 days were associated with significantly poorer mental health status (-4.9 points, $95 \% \mathrm{Cl}-6.5$ to -3.2$)$ but not with poorer physical health status $(-0.03$ points, $95 \% \mathrm{Cl}-1.3$ to 1.3$)$ ).

Conclusions: Drug use is common among homeless individuals in Toronto. Current drug problems are associated with poorer mental health status but not with poorer physical health status.
\end{abstract}

\section{Background}

Drug use is believed to be an important factor contributing to the poor health and increased mortality risk that has been widely observed among homeless individuals $[1,2]$. Substance use may increase the risk of homelessness by undermining their social ties and economic stability [3]. Drug users also suffer from numerous adverse health effects, including overdoses, psychiatric conditions, and infectious diseases $[4,5]$.

Drug use patterns vary regionally and often change over time [6]. However, few recent studies in the peer-reviewed

\footnotetext{
* Correspondence: michelle.grinman@utoronto.ca

${ }^{1}$ Centre for Research on Inner City Health, The Keenan Research Centre in the Li Ka Shing Knowledge Institute of St. Michael's Hospital, Toronto, Canada
}

(c) 2010 Grinman et al; licensee BioMed Central Ltd. This is an Open Access article distributed under the terms of the Creative

literature have examined patterns of drug use among homeless individuals in a major Canadian city. This study's goal was to determine the prevalence and characteristics of drug use among a stratified random sample of homeless individuals in Toronto. The prevalence of drug problems, as determined by the Addiction Severity Index, was also ascertained, and the association between drug problems and physical and mental health status was examined.

\section{Methods \\ Sampling design}

This study was part of a larger ongoing study of health care utilization among homeless individuals. For this reason, the study recruited a stratified random sample of homeless persons in Toronto in 2004-2005 who were 
registered with the province of Ontario's universal health insurance program [7]. Homelessness was defined as living within the last 7 days at a shelter, public place, vehicle, abandoned building, or someone else's residence, and not having a place of one's own. Approximately $90 \%$ of study participants were recruited at shelters and $10 \%$ at meal programs. These proportions were based on pilot data showing that $90 \%$ of homeless individuals in Toronto slept at shelters and 10\% used meal programs but not shelters [8]. Recruitment was stratified to obtain a 2:1:1 ratio of males without dependent children, females without dependent children, and adults accompanied by dependent children to ensure adequate power for comparisons among these three groups. When a family with dependent children included two or more adults, one adult was randomly selected for inclusion in the analysis.

Permission to recruit participants was granted by 58 (91\%) of 64 shelters in Toronto for men, women, youth, and families. Recruitment also took place at 18 meal programs randomly selected from 62 sites serving homeless people. The number of participants recruited at each site was proportionate to the number of homeless individuals served monthly at that site. Participants were selected from bed lists or meal lines using a random number generator and then screened for eligibility. Because the goal of recruiting at meal programs was to enroll homeless people who did not use shelters, we excluded individuals at meal programs who had used a shelter within the last 7 days.

Of 2,516 individuals screened at homeless shelters and meal programs, 882 individuals (35\%) were ineligible for the following reasons: 229 (9\%) did not meet our definition of homelessness, 104 (4\%) were unable to communicate in English, 54 (2\%) were homeless shelter users encountered at meal programs, $53(2 \%)$ were unable to give informed consent, and $442(18 \%)$ were excluded because they did not have an Ontario health insurance number. A health insurance number was required to allow tracking of participants' use of the health care system, since this was the main goal of the primary study of which this was a part. Those excluded due to lack of a health insurance number consisted mainly of refugees, refugee claimants, or recent migrants to Ontario. Of 1,634 eligible individuals, 443 declined to participate and 1,191 individuals (73\% of those eligible) were enrolled in the study. Each participant provided written informed consent and received \$15 for completing the survey. This study was approved by the research ethics board at St. Michael's Hospital in Toronto, Canada.

\section{Survey instrument}

Demographic characteristics were obtained by self-report. Race/ethnicity was self-identified, with participants selecting from categories from the Statistics Canada Ethnic Diversity Survey [9]. Participants identified the first and second most important factors that they felt were keeping them from getting out of homelessness. Their free responses were coded into mutually exclusive categories, including lack of employment, lack of suitable housing, and addiction to drugs and/or alcohol.

Details were obtained about drug use, including the types of substances ever used, how recently each drug had been used, and frequency of use in the last 30 days. We differentiated between drug use and drug problems. The Addiction Severity Index (ASI), which identifies individuals whose daily functioning is affected by their drug use, was used to determine whether participants had current drug problems (ie. within the last 30 days) $[10,11]$. For example, the ASI includes questions regarding the effects of drug use on physical health (such as adverse drug reactions or black outs), social interactions (such as loss of friends or neglect of family), and integration into society (such as missed work or illegal activities) [10]. This instrument has been validated in studies of homeless individuals [12-14]. Drug problems were dichotomized as present or absent based on criteria previously used with homeless populations [15]. The ASI was also used to determine whether participants had mental health problems or alcohol problems in the last 30 days $[10,11]$.

The SF-12, a widely used general health status instrument that has been validated in homeless populations, $[16,17]$ was used to generate measures of physical health status (physical component subscale (PCS)) and mental health status (mental component subscale (MCS)). These scores range from 13 to 69 for physical health and 10 to 70 for mental health, standardized to a mean of 50 and standard deviation of 10 in the general population in the United States [17].

\section{Statistical analyses}

Data analyses were performed using SPSS 16.0. Prevalence of drug use was classified as recent (within the past 2 years) or remote ( $>2$ years ago). For each drug type, the median number of episodes of use in the past 30 days was calculated. Characteristics of participants with and without drug problems were compared using chi-square and t-tests. Linear regression models were constructed to determine if current drug problems were associated with physical health status or mental health status, after adjustment for age, sex, race/ethnicity, and level of education.

\section{Results}

Lifetime prevalence of regular use of at least one drug was reported by 712 individuals (60\%). In contrast, 
current drug problems (i.e., within the last 30 days) were present in 475 individuals (40\%). The prevalence of current drug problems varied widely by sex and family status: $53 \%$ among single men, $41 \%$ among single women, and $12 \%$ among adults accompanied by dependent children. A comparison of characteristics of individuals with and without a current drug problem revealed numerous differences (Table 1). Individuals with current drug problems were significantly more likely to be single men, white, Canadian-born, and lacking a high school degree. They were also more likely to be younger and to have become homeless at a younger age. Participants with current drug problems had a longer lifetime duration of homelessness (mean 4.8 vs. 2.9 years, $\mathrm{p}<0.001$ ). Alcohol problems within the last 30 days were present among $45 \%$ of individuals with current drug problems, compared to $19 \%$ among those without current drug problems $(\mathrm{p}<0.001)$. Among individuals with drug problems in the last 30 days, only $27 \%$ identified drug and/ or alcohol use as a factor keeping them from getting out of homelessness.
Prevalence of drug use is shown in Figure 1, by specific substance. The substances most commonly used within the past 2 years were marijuana (40\%), cocaine (27\%), and opiate analgesics other than heroin or methadone (i.e., oxycodone, hydromorphone, meperidine, codeine, and pentazocine) (8\%). Drug use within the past 2 years varied by demographic group, with marijuana use reported by $51 \%$ of single men, $35 \%$ of single women, and $21 \%$ of adults with dependent children ( $\mathrm{p}<$ 0.001 ). Cocaine use was $32 \%, 32 \%$, and $9 \%$, respectively ( $\mathrm{p}<0.001)$. Opiate use was $11 \%, 8 \%$, and $4 \%$, respectively ( $\mathrm{p}=0.016)$.

Figure 2 shows the median number of days of drug use within the past 30 days, among individuals reporting any use during that time frame. Marijuana and cocaine had the highest reported use in the last 30 days (median of 15 and 9 episodes, respectively). In contrast, heroin, methadone and other opiates were used a median of 7 , 6 , and 5 episodes in the past 30 days, respectively.

Physical health status and mental health status, as measured by the SF-12, are shown in Table 2. In

Table 1 Characteristics of study participants. Data are given as numbers (\%), unless otherwise specified

\begin{tabular}{|c|c|c|c|c|}
\hline & $\begin{array}{l}\text { All participants } \\
(\mathrm{N}=1191)\end{array}$ & $\begin{array}{l}\text { With current drug } \\
\text { problem }(n=475)\end{array}$ & $\begin{array}{l}\text { Without current drug } \\
\text { problem }(n=716)\end{array}$ & p-value \\
\hline Age, mean (SD) & $36.2(12.3)$ & $34.2(11.1)$ & $37.5(12.9)$ & $<0.001$ \\
\hline Sex/family status & & & & $<0.001$ \\
\hline Single male & $603(50.6)$ & $317(66.7)$ & $286(39.9)$ & \\
\hline Single female & $304(25.5)$ & $125(26.3)$ & $179(25.0)$ & \\
\hline Adult accompanied by children & $283(23.7)$ & $33(6.9)$ & $250(34.9)$ & \\
\hline Race/ethnicity & & & & $<0.001$ \\
\hline White & $662(55.6)$ & $300(63.2)$ & $362(50.6)$ & \\
\hline Black & $266(22.3)$ & $72(15.2)$ & $194(27.1)$ & \\
\hline First Nations & $100(8.4)$ & $60(12.6)$ & $40(5.6)$ & \\
\hline Other race/ethnicity & $163(13.7)$ & $43(9.1)$ & $120(16.8)$ & \\
\hline Region of birth & & & & $<0.001$ \\
\hline Canada & $812(68.2)$ & $392(82.5)$ & $420(58.7)$ & \\
\hline Outside Canada & $379(31.8)$ & $83(17.5)$ & $296(41.3)$ & \\
\hline Education & & & & $<0.001$ \\
\hline Some high school or less & $597(50.3)$ & $290(61.3)$ & $307(42.9)$ & \\
\hline High school or equivalent & $255(21.5)$ & $92(19.5)$ & $163(22.8)$ & \\
\hline Vocational training/college or above & $336(28.3)$ & $91(19.2)$ & $245(34.3)$ & \\
\hline Age at first episode of homelessness, mean (SD) & $28.4(13.0)$ & $24.8(11.9)$ & $30.9(13.2)$ & $<0.001$ \\
\hline $\begin{array}{l}\text { Duration of current episode of homelessness in } \\
\text { months, mean (SD) }\end{array}$ & $15.7(35.2)$ & $18.7(37.2)$ & $13.8(33.7)$ & 0.02 \\
\hline Lifetime years of homelessness in years, mean (SD) & $3.7(5.5)$ & $4.8(5.6)$ & $2.9(5.2)$ & $<0.001$ \\
\hline $\begin{array}{l}\text { Drugs and alcohol reported as an impediment from } \\
\text { getting out of homelessness }\end{array}$ & $162(13.6)$ & $128(26.9)$ & $34(4.7)$ & $<0.001$ \\
\hline Simultaneous use of $>1$ drug in past month* & $501(42.1)$ & $363(76.4)$ & $138(19.3)$ & $<0.001$ \\
\hline Mean pack-years smoked (SD) & $17.8(29.6)$ & $21.5(24.6)$ & $15.4(32.3)$ & $<0.001$ \\
\hline $\begin{array}{l}\text { Mental health problems (present within the last } \\
30 \text { days) }\end{array}$ & $444(37.3)$ & $212(44.6)$ & $232(32.4)$ & $<0.001$ \\
\hline
\end{tabular}

\footnotetext{
* This question was only asked of participants who had ever used drugs in their lifetime.
} 


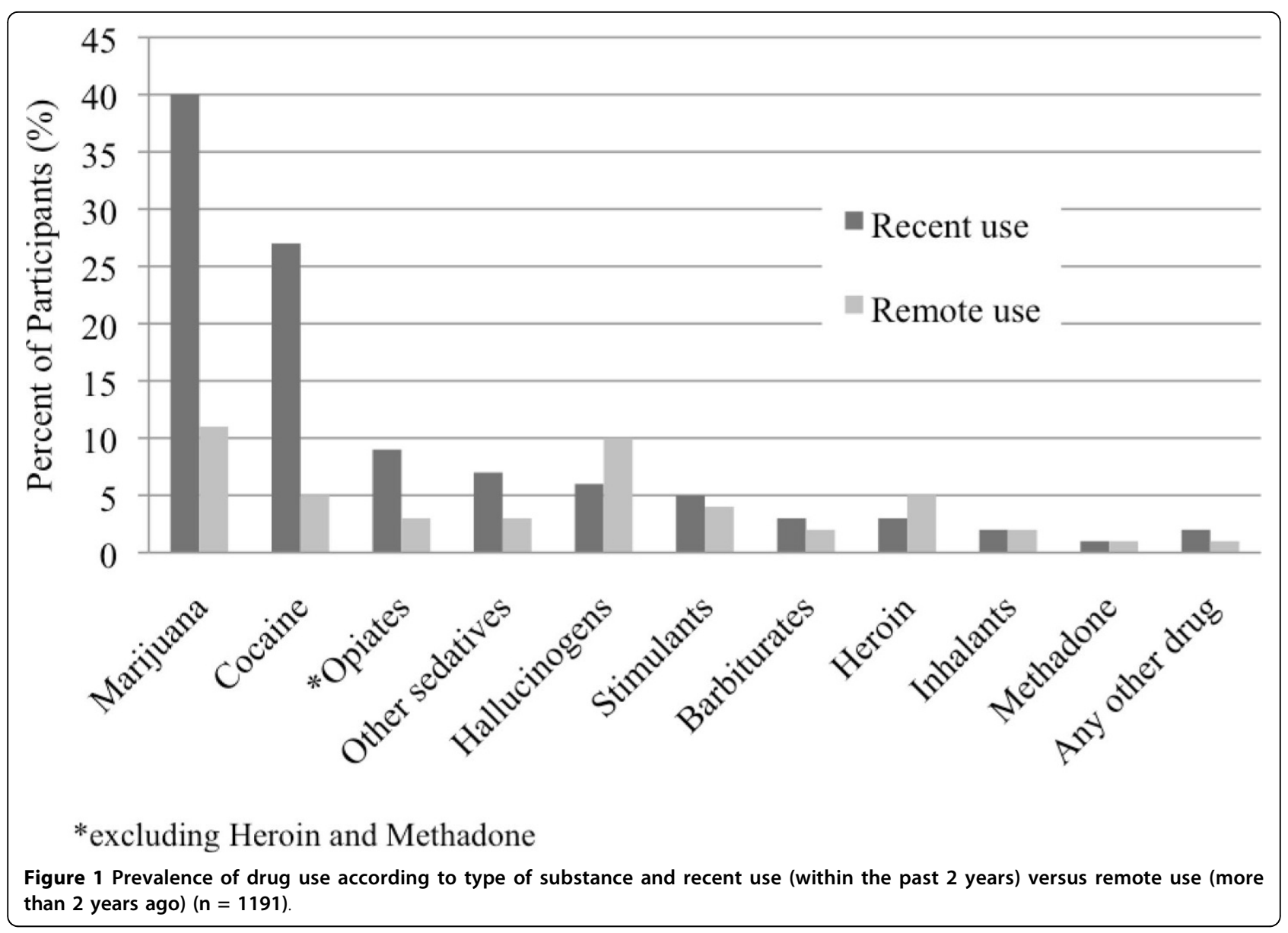

univariate analysis, drug problems were associated with significantly lower mental health status. In linear regression models adjusted for age, sex, level of education, and race/ethnicity, having current drug problems was associated with significantly poorer mental health (MCS -4.9 points, $95 \%$ CI -6.5 to -3.2 ) but not with poorer physical health (PCS $-0.03,95 \%$ CI -1.3 to +1.3 ). A similar pattern was observed in models examining the association between cocaine use and mental and physical health scores (MCS -4.7 points, 95\% CI -6.4 to -3.0 ; PCS -1.3 points, $95 \%$ CI -2.7 to +0.06 ).

\section{Discussion}

The prevalence of drug use was found to be very high among homeless individuals in Toronto compared to rates previously reported for the general population. Lifetime drug use among participants was $60 \%$; in contrast, a study by Vega and colleagues (2002) on the prevalence of drug use at 7 international sites found rates of $32 \%$ for men and $20 \%$ for women in the province of Ontario [18]. A similar pattern was observed for the use of specific drugs. The prevalence of cocaine use within the past 2 years among study participants (27\%) was 27 - fold higher than the corresponding figure of $1 \%$ in the general Canadian population, as reported by the Toronto Drug Strategy Advisory Committee (2005) [19]. Regular marijuana use (40\%) was almost three times higher than that found in the general population (14\%) in the 2006 Canadian Addiction Survey [20].

High rates of drug use among homeless people result from a number of processes. Drug use is a risk factor for becoming homeless [21]. Drug use is also a risk factor for prolonged homelessness [22], which is confirmed by our data. As a result of this association, drug users are over-represented in cross-sectional surveys of homeless populations [23]. Homelessness may increase the likelihood that an individual will use drugs.

However, only about one-quarter of participants with current drug problems identified drug and/or alcohol use as an impediment to acquiring stable housing, which is consistent with a recent survey of 368 homeless individuals in Toronto in which only $23 \%$ of participants identified their drug or alcohol use as the main reason for becoming homeless [24]. Some homeless individuals may be in a state of denial or lack insight regarding the impact of their substance use. Alternatively, this finding 


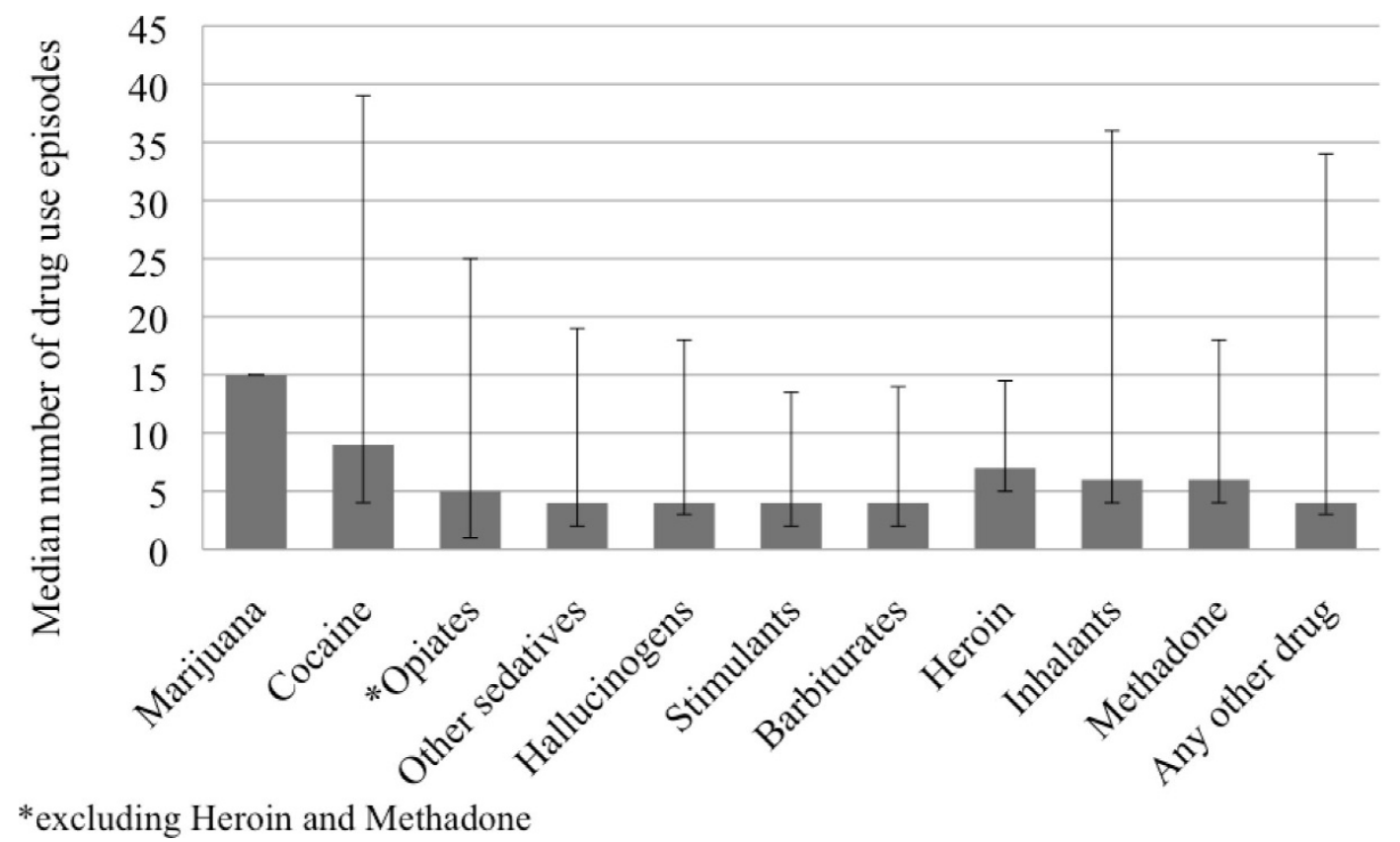

Figure 2 Intensity of drug use within the past 30 days represented as mean number of episodes of drug use with $25^{\text {th }}$ and $75^{\text {th }}$ quartiles for each drug category.

Table 2 Associations between current drug problem and health status, as measured by SF-12 scores

\begin{tabular}{|c|c|c|}
\hline & $\begin{array}{l}\text { Physical } \\
\text { Component } \\
\text { Subscale }\end{array}$ & $\begin{array}{c}\text { Mental } \\
\text { Component } \\
\text { Subscale }\end{array}$ \\
\hline & Mean (SD) & Mean (SD) \\
\hline Current drug problem & $46.6(10.6)$ & $38.8(12.9)$ \\
\hline $\begin{array}{l}\text { Without current drug } \\
\text { problem }\end{array}$ & $45.7(11.4)$ & $42.0(13.2)$ \\
\hline$p$-value & 0.17 & $<0.001$ \\
\hline Recent cocaine use & $44.8(11.4)$ & $38.1(12.7)$ \\
\hline No recent cocaine use & $46.5(11.0)$ & $41.7(13.2)$ \\
\hline \multirow[t]{2}{*}{$p$-value } & 0.02 & $<0.001$ \\
\hline & Beta $(95 \% \mathrm{Cl})$ & Beta $(95 \% \mathrm{Cl})$ \\
\hline \multicolumn{3}{|c|}{ Change in SF-12 score associated with } \\
\hline Current drug problem* & $-0.03(-1.3$ to +1.3$)$ & $-4.9(-6.5$ to -3.2$)$ \\
\hline Recent cocaine use* & $-1.3(-2.7$ to +0.06$)$ & $-4.7(-6.4$ to -3.0$)$ \\
\hline
\end{tabular}

* In linear regression models adjusted for sex, age, level of education, and race/ethnicity.

may reflect the multifactorial causes of homelessness. Either of these possibilities has practical implications for assisting homeless individuals with drug problems. There is controversy regarding the effectiveness of adopting a "housing first" approach versus interventions that require substance abuse treatment and/or abstinence from drug use as a pathway to obtaining stable housing [25].
As expected, drug problems were associated with significantly poorer mental health status. The lack of association between drug problems and physical health status is surprising given the many physical health complications related to drug use [4,5]. This finding may be explained by a long latency period between the initiation of drug use and deterioration in physical health, survival bias due to the death of drug users with poor physical health, or selection bias due to the exclusion of hospitalized individuals. Nonetheless, our findings suggest that service providers should recognize that mental health, rather than physical health, may represent the greatest challenge for homeless individuals with drug problems.

This study has a number of strengths. A large stratified random sample of homeless men and women, including both shelter and non-shelter users, were recruited across numerous community sites in a major North American city. The recruitment rate of eligible individuals was very high at $73 \%$. Also, the ASI instrument utilized in this study has been previously validated among homeless people [12-14].

This study has a few limitations. There was no control group of non-homeless individuals. The exclusion of individuals who were unable to give informed consent may have resulted in the elimination of people who were under the influence of drugs. The requirement that study participants have a health insurance number resulted in the exclusion of refugees and refugee 
claimants. Lastly, drug use was assessed on the basis of self-report. While this method is subject to recall errors and social desirability bias, it has been validated as a fairly accurate measure among homeless individuals [12].

\section{Conclusions}

Our study demonstrates the high prevalence of drug use among the homeless population of Toronto. Drug use is associated with a substantial negative impact on mental health, as well as earlier onset and longer duration of homelessness. These findings suggest the need for early interventions aimed at preventing initiation of street drug use. Improved access to drug treatment programs for homeless individuals is also needed.

\section{Acknowledgements}

This project was supported by operating grants from the Agency for Healthcare Research and Quality (1 R01 HS014129-01) and the Canadian Institutes of Health Research (MOP-62736), and by an Interdisciplinary Capacity Enhancement grant on Homelessness, Housing, and Health from the Canadian Institutes of Health Research (HOA-80066). The Centre for Research on Inner City Health and the Institute for Clinical Evaluative Sciences gratefully acknowledge the support of the Ontario Ministry of Health and Long-Term Care. Dr. Redelmeier is supported by the Canada Research Chair in Medical Decision Sciences. The authors thank Marko Katic, Department of Research Design and Biostatistics, Sunnybrook Health Sciences Centre, for expert programming and analyses. The authors also thank the shelters and meal programs that allowed the recruitment of participants and the interviews to be conducted at their sites.

\section{Author details}

${ }^{1}$ Centre for Research on Inner City Health, The Keenan Research Centre in the Li Ka Shing Knowledge Institute of St. Michael's Hospital, Toronto, Canada. ${ }^{2}$ Department of Medicine, University of Toronto, Toronto, Canada. ${ }^{3}$ Sunnybrook Health Sciences Centre, Institute for Clinical Evaluative Sciences, Toronto, Canada. ${ }^{4}$ Department of Research Design and Biostatistics, Institute for Clinical Evaluative Sciences, Sunnybrook Health Sciences Centre, Toronto, Canada. ${ }^{5}$ Crohn's and Colitis Foundation of Canada, Toronto, Canada. ${ }^{6}$ Department of Psychiatry, University of Toronto, Toronto, Canada. ${ }^{7}$ Street Health Community Nursing Foundation, Toronto, Canada.

\section{Authors' contributions}

SC, DAR, WL, AK, GT, LC, and SWH contributed to the study concept and design, and critically reviewed the manuscript for important intellectual content. MNG performed the statistical analysis, data interpretation, as well as the drafting and critical review of the manuscript for important intellectual content. SC oversaw the study data collection, and conducted the statistical analysis. SWH supervised the overall study and the statistical analysis, and interpreted the data. All authors reviewed the manuscript personally and agreed to its publication.

\section{Competing interests}

The authors declare that they have no competing interests.

The funders for this study did not play any role in the study design, in the collection, analysis, and interpretation of data; in the writing of the report; and in the decision to submit the article for publication. The views expressed in this publication are the views of the authors and do not necessarily reflect the views of the Ontario Ministry of Health and LongTerm Care or any of the other organizations that have been acknowledged.

\section{References}

1. Hwang SW: Mortality among men using homeless shelters in Toronto, Ontario. JAMA 2000, 283(16):2152-7.

2. Galea S, Vlahov D: Social determinants and health of drug users: Socioeconomic status, homelessness and incarceration. Public Health Reports 2002, 117(1 supplement 1):S135-145.

3. Vangeest JB, Johnson TP: Substance Abuse and Homelessness: Direct or Indirect Effects? Substance abuse and homelessness. AEP 2002, 12(7):455-46.

4. Chyvette TW, Latkin CA: Neighbourhood Socioeconomic Status, Personal Network Attributes, and Use of Heroin and Cocaine. Am J Prev Med 2007, 32(6S).

5. Little M, Shah R, Vermeulen MJ, Gorman A, Dzendoletas D, Ray JG: Adverse perinatal outcomes associated with homelessness and substance use in pregnancy. CMAJ 2005, 173(6):615-8.

6. Drug Trends and the CCENDU network: 2002 National Report. Canadian Community Epidemiology Network on Drug Use (CCENDU). Canadian Centre on Substance Abuse http://www.ccsa.ca/2003\%20and\%20earlier\%20CCSA\% 20Documents/CCENDU-National-2002-e.pdf, accessed 2008 July 16.

7. Hwang SW, Colantonio A, Chiu S, Tolomiczenko G, Kiss A, Cowan L, Redelmeier $D$, Levinson $\mathrm{W}$ : The effect of traumatic brain injury on the health of homeless people. CMAJ 2008, 179(8).

8. Hwang SW, Chiu S, Kiss A, Katic M, Tolomiczenko G, Levinson W, Redelmeier D, Szalai JP, Cowan L: Use of meal programs and shelters by homeless people in Toronto [abstract]. J Urban Health 2005, 82(Suppl 2): ii46.

9. Statistics Canada: Ethnic Diversity Survey Questionnaire. 2002http://www. statcan.gc.ca/, (accessed 2007 Sept 11).

10. McGahan PL, Griffith JA, Parente R, McLellan AT: Addiction Severity Index: Composite Scores Manual. Philadelphia: The University of Pennsylvania/ Veterans Administration Centre for Studies of Addictionhttp://www. tresearch.org/resources/compscores/CompositeManual.pdf, (accessed 2007 Sept 4).

11. McLellan AT, Kushner H, Metzger D, Peters R, Smith I, Grissom G, Pettinati H, Argerious M: The fifth edition of the Addiction Severity Index. J Subst Abuse Treat 1992, 9:199-213.

12. Zanis DA, McLellan AT, Canaan RA, Randall M: Reliability and validity of the Addiction Severity Index with a homeless sample. J Subst Abuse Treat 1994, 11:541-8.

13. Joyner LM, Wright JD, Devine JA: Reliability and validity of the addiction severity index among homeless substance misusers. Subst Use Misuse 1996, 31:729-51.

14. Drake RE, McHugo GJ, Biesanz JC: The test-retest reliability of standardized instruments among homeless persons with substance use disorders. J Stud Alcohol 1995, 56:161-7.

15. Burt MR, Aron LY, Douglas T: Homelessness: Programs and the People They Serve. Findings of the National Survey of Homeless Assistance Providers and Clients. Washington: United States Interagency Council on the Homelessness 1999.

16. Larson CO: Use of the SF-12 Instrument for Measuring the Health of Homeless Persons. Health Services Research 2002, 37:733-49.

17. Ware JE, Kosinski M, Keller SD: SF-12: How to Score the SF-12 Physical and Mental Health Summary Scales. Boston: The Health Institute, New England Medical Center, 21995

18. Vega W, Aguilar-Gaxiola S, Andrade L, Bijl R, Borges G, Caraveo-Anduaga JJ, DeWit DJ, Heeringa SG, Kessler RC, Kolody B, Merikangas KR, Molnar BE, Walters EE, Warner LA, Wittchen HU: Prevalence and age of onset for drug use in seven international sites: results from the international consortium of psychiatric epidemiology. Drug and Alcohol Dependence 2002, 68:285-297.

19. The Toronto Drug Strategy - Appendix E: Substance use in Toronto: Issues, Impacts and Interventions. Toronto Drug Strategy Advisory Committee Report 2005

20. Canadian Addiction Survey. Canadian Centre on Substance Abuse 2006http://www.ccsa.ca/Eng/Priorities/Research/CanadianAddiction/Pages/ default.aspx, Accessed 2008 Dec 20.

21. Shelton KH, Taylor PJ, Bonner A: Risk factors for homelessness: evidence from a population-based study. Psychiatric Services 2009, 60(4):465-72. 
22. Caton CL, Dominguez B, Schanzer B, Hasin DS, Shrout PE, Felix A, McQuistion H, Opler LA, Hsu E: Risk factors for long-term homelessness: findings from a longitudinal study of first-time homeless single adults. Am J Public Health 2005, 95(10):1753-9.

23. Phelan JC, Link BG: Who are "the homeless"? Reconsidering the stability and composition of the homeless population. Am J Public Health 1999, 89(9):1334-8.

24. Khandor E, Mason K, Cowan L, Hwang SW: Street Health Report. Toronto 2007.

25. Kertesz S, Crouch K, Milby JB, Cusimano RE, Schumacher JE: Housing First for Homeless Persons with Active Addiction: Are We Overreaching?.

Milbank Q 2009, 87(2):495-534.

\section{Pre-publication history}

The pre-publication history for this paper can be accessed here:http://www. biomedcentral.com/1471-2458/10/94/prepub

doi:10.1186/1471-2458-10-94

Cite this article as: Grinman et al:: Drug problems among homeless individuals in Toronto, Canada: prevalence, drugs of choice, and relation to health status. BMC Public Health 2010 10:94.

\section{Submit your next manuscript to BioMed Central} and take full advantage of:

- Convenient online submission

- Thorough peer review

- No space constraints or color figure charges

- Immediate publication on acceptance

- Inclusion in PubMed, CAS, Scopus and Google Scholar

- Research which is freely available for redistribution

Submit your manuscript at www.biomedcentral.com/submit 